\title{
Determination of Photoperiod-sensitive Stages of Development of the Short-day Plant Celosia
}

\author{
Ryan M. Warner ${ }^{1}$ \\ Department of Horticulture, Michigan State University, A234 Plant and Soil \\ Science, East Lansing, MI 48824
}

Additional index words. Celosia argentea var. plumosa, flowering, floral induction, limited inductive photoperiod, juvenility

\begin{abstract}
Celosia argentea L. var. plumosa Voss. (celosia) is a bedding plant crop that often exhibits premature flowering during commercial production, resulting in plants of unacceptable quality. Celosia is a facultative short-day plant. Understanding the photoperiod-sensitive stages of development is critical for management of photoperiodic crops. Limited inductive photoperiod experiments, in which photoperiodic plants are moved from noninductive to inductive conditions for flowering at varying stages of development and for varying durations before returning to noninductive conditions, were conducted to determine when celosia becomes sensitive to floral-inducing short days and how many photoinductive cycles are necessary for floral induction. Plants became receptive to short days $\approx 9$ to 12 days after seedling emergence (DAE). Between six and nine short photoperiods beginning 9 DAE were sufficient to commit plants to flowering, depending on the cultivar evaluated. Early flowering was highly correlated with reductions in plant quality parameters, including the number of inflorescences produced, the number of lateral branches, and shoot dry weight. By the time plants had developed five nodes, photoperiod no longer impacted time to flower, indicating that celosia remains photoperiod-sensitive for floral induction only from $\approx 9$ to $45 \mathrm{DAE}$ at $20{ }^{\circ} \mathrm{C}$.
\end{abstract}

Timing of flowering in plants is the result of an integration of internal and external signals (Kobayashi and Weigel, 2007). Flowering of many plant species is synchronized temporally through changes in night length (Garner and Allard, 1920), a phenomenon termed photoperiodism. Proper timing of flowering is critical for ornamental crop species, particularly bedding plant species, which have a narrow sales period in late spring. Annual bedding plant species exhibit a wide range of photoperiodic responses (Erwin and Warner, 2002; Mattson and Erwin, 2005). This presents greenhouse growers with the considerable challenge of simultaneously producing flowering crops of species with different photoperiodic requirements for floral induction.

For photoperiodic plants, timing of floral induction is determined by the length of the juvenile phase, the phase of plant development beginning at germination when plants are incapable of flowering regardless of the growth conditions (Thomas and Vince-Prue, 1997), and exposure of mature plants to at least a minimum number of appropriate day/

\footnotetext{
Received for publication 15 Oct. 2008. Accepted for publication 10 Dec. 2008.

I acknowledge C. Raker and Sons for providing plant materials, financial support from the Michigan Agricultural Experiment Station and greenhouse growers supportive of floriculture research at Michigan State University, and Mike Olrich for technical assistance.

${ }^{1}$ Assistant Professor.

e-mail warnerry@msu.edu.
}

night length cycles (i.e., inductive photoperiods). Both the length of the juvenile phase and the number of inductive photoperiods required for floral induction to occur in mature plants vary widely across plant species.

The duration of the juvenile phase varies from only days for species such as Brassica campestris L. 'Ceres' (Friend, 1968) and Chenopodium rubrum L. (Cumming, 1959) to several years for many tree species (Clark, 1983). For herbaceous annual and perennial bedding plants, the length of the juvenile phase is often defined in terms of the number of leaves or nodes that must develop before plants are sensitive to floral-inducing conditions (Thompson and Stout, 1991). The length of the juvenile phase and the minimum number of inductive photoperiod cycles necessary for floral initiation can be determined with limited inductive photoperiod or reciprocal transfer experiments, in which plants are exposed to varying numbers of inductive photoperiod cycles before being transferred back to noninductive conditions (Damann and Lyons, 1993). Reciprocal transfer experiments have been used to identify photoperiod-sensitive stages of development for numerous crops, including Dendranthema $\times$ grandiflora Tzvelv. (chrysanthemum) (Adams et al., 1998), Papaver somniferum L. (Wang et al., 1997), and Petunia $\times$ hybrida Vilm. (petunia) (Adams et al., 1999).

Similar to juvenile period length, there is great variability in the number of photoinductive cycles necessary to induce flowering among photoperiodic plant species. Some species, including the short-day plants Phar- bitis nil 'Violet' Chois., Chenopodium rubrum L., and Xanthium strumarium L., can be induced by a single short photoperiod (Thomas and Vince-Prue, 1997), making these species of tremendous usefulness for studying the physiology and genetics of photoperiodic floral induction. In contrast, strawberry (Fragaria ×ananassa Duch.) requires between 7 and 23 short days for floral induction, depending on genotype, temperature conditions, and plant age (Hartmann, 1947; Ito and Saito, 1962; Verheul et al., 2006). In addition to differences in minimum inductive photoperiod number, there is often a quantitative relationship between the number of inductive photoperiods received and the strength of the flowering response either in terms of the number of flowers produced per inflorescence and/or the number of inflorescences produced (Verheul et al., 2006). For example, as the number of short days $P$. nil 'Kidachi' were exposed to increased from 1 to $5 \mathrm{~d}$, the flower bud number increased from two to six buds, although timing of flowering was unaffected (Imamura et al., 1966).

Selection for early flowering has long been a breeding objective for many greenhouse crops (Anderson, 2006). However, premature flowering (defined here as flowering before commercially desirable) in the greenhouse often reduces quality parameters of spring bedding plant crops such as the number of flowers and branches. Celosia argentea L. var. plumosa Voss (celosia) is a facultative (or quantitative) short-day plant (Piringer and Borthwick, 1961). Celosia often exhibits premature flowering in greenhouses during late winter and early spring, when the natural photoperiod is short. The early flowering observed in celosia suggests that plants become receptive to floralinducing short days early in development. It is critical to understand the photoperiodsensitive stages of development to properly control development of photoperiodic crops such as celosia. Therefore, the objectives of the work presented here were to determine: 1) when in development $C$. argentea var. plumosa becomes sensitive to photoperiod for floral induction; 2) the minimum number of short-day cycles necessary for floral induction; and 3) the impact of early flowering on phenotypic characteristics associated with crop quality.

\section{Materials and Methods}

Expt. 1: Photoperiod treatments. Celosia argentea var. plumosa 'Gloria Scarlet' seedlings were received from a commercial supplier (C. Raker \& Sons, Litchfield, MI) in 128cell $(10-\mathrm{mL})$ plug trays when the cotyledons were expanded (parallel to the media surface). Seedlings were then transplanted into $9-\mathrm{cm}$ square pots $(376 \mathrm{~mL})$ containing $(\mathrm{v} / \mathrm{v}) 70 \%$ peatmoss, $21 \%$ vermiculite, and $9 \%$ perlite (Sure-Mix, Michigan Grower Products, Galesburg, MI) and maintained under a noninductive long-day photoperiod (LD; 9-h photoperiod obtained by covering plants with 
opaque cloth from 1700 to 0800 HR daily and adding $2 \mu \mathrm{mol} \cdot \mathrm{m}^{-2} \cdot \mathrm{s}^{-1}$ night-interruption lighting from incandescent lamps from 2200 to $0200 \mathrm{HR})$ at $20 \pm 1{ }^{\circ} \mathrm{C}(24$-h average \pm SD $)$ until the first true leaf pair unfolded, at which time photoperiod treatments began. Plants were either grown continuously under a short-day photoperiod (SD; a truncated 9-h photoperiod obtained by covering plants with opaque cloth from 1700 to $0800 \mathrm{HR}$ daily) or constant LD or exposed to a limited inductive photoperiod treatment. Limited inductive photoperiod treatments consisted of moving plants from LD to SD when plants had unfolded one, two, three, four, or five leaf pairs and maintaining them under SD for 5, 10, $15,20,25$, or $30 \mathrm{~d}$. After the SD exposures, plants were moved back to LD where they remained until flowering. The experiment consisted of 10 plants per treatment.

Plant culture. Plants were irrigated as needed with reverse osmosis-treated well water supplemented with $125 \mathrm{mg} \cdot \mathrm{L}^{-1}$ nitrogen $(\mathrm{N})$, $13 \mathrm{mg} \cdot \mathrm{L}^{-1}$ phosphorus $(\mathrm{P}), 125 \mathrm{mg} \cdot \mathrm{L}^{-1}$ potassium $(\mathrm{K}), 15 \mathrm{mg} \cdot \mathrm{L}^{-1}$ calcium $(\mathrm{Ca}), 1 \mathrm{mg} \cdot \mathrm{L}^{-1}$ iron (Fe), 0.1 boron (B) and molybdenum (Mo), and $0.5 \mathrm{mg} \cdot \mathrm{L}^{-1}$ manganese $(\mathrm{Mn})$, zinc $(\mathrm{Zn})$, and copper $(\mathrm{Cu})$ (MSU Special; GreenCare Fertilizers, Kankakee, IL).

Data collection and analysis. The number of nodes on the primary shoot below the terminal inflorescence and the number of visible lateral inflorescences were determined. The experiment used a factorial statistical design with timing of SD exposure (five levels) and SD duration (six levels) as main effects for a total of 30 treatments plus constant LD and SD controls. Analysis of variance was conducted using the general linear model procedure of the SPSS 16.0 for Windows statistical software package (SPSS Inc., Chicago, IL).

Expt. 2. Celosia argentea var. plumosa 'Fresh Look Red' and 'Gloria Scarlet' seeds were sown at a commercial supplier (C. Raker and Sons, Inc.) in 128-cell plug trays. The day after sowing, seedling trays were transported to Michigan State University and placed in a greenhouse maintained at $23 \pm 1{ }^{\circ} \mathrm{C}$ under intermittent mist until germination. On germination, seedlings were selected to include only those that germinated on the same day (5 June 2006) and photoperiod treatments began. Plants were grown at $20{ }^{\circ} \mathrm{C}$ under constant SD (SD and LD were as described for Expt. 1), constant LD, or grown under LD, moved into SD beginning $0,3,6,9$, or 12 $\mathrm{d}$ after emergence (DAE) for $1,3,6,9$, or $12 \mathrm{~d}$, then moved back to LD until flowering. All photoperiod treatments were conducted on plants in plug cells. Plug trays were cut into four-cell packs. The experiment consisted of three cell packs of four plants per treatment (total 12 plants per treatment). After the photoperiod treatments ended (24 DAE), plants were transplanted into $9-\mathrm{cm}$ square pots and grown under LD until flowering.

Plant culture. During the photoperiod treatments, seedling plug packs were grown on top of capillary matting saturated with reverse-osmosis water supplemented with 50 $\mathrm{mg} \cdot \mathrm{L}^{-1} \mathrm{~N}, 5 \mathrm{mg} \cdot \mathrm{L}^{-1} \mathrm{P}, 20 \mathrm{mg} \cdot \mathrm{L}^{-1} \mathrm{~K}, 6 \mathrm{mg} \cdot \mathrm{L}^{-1}$ $\mathrm{Ca}, 0.4 \mathrm{mg} \cdot \mathrm{L}^{-1} \mathrm{Fe}, 0.04 \mathrm{~B}$ and $\mathrm{Mo}$, and 0.2 $\mathrm{mg} \cdot \mathrm{L}^{-1} \mathrm{Mn}, \mathrm{Zn}$, and $\mathrm{Cu}$ (MSU Special; GreenCare Fertilizers). After transplanting into 9-cm square pots (24 DAE), plants were grown as described for Expt. 1.

Data collection and analysis. When the terminal inflorescence was $4 \mathrm{~cm}$ in length, the date was recorded and the number of nodes below the terminal inflorescence, number of visible inflorescences, and the number of branches (greater than $3 \mathrm{~cm}$ in length) were determined. After data collection, the shoot tissue was harvested, dried in an oven at $70{ }^{\circ} \mathrm{C}$ for at least $72 \mathrm{~h}$, and the shoot dry weight was determined. Analyses of variance were performed as described for Expt. 1. To identify limited inductive photoperiod treatments resulting in a similar node number below the first inflorescence as plants grown under constant SD, Dunnett's test was performed using the constant SD treatment as the reference group.

\section{Results}

Expt. 1. For limited inductive photoperiod treatments timing, but not duration, of SD exposures impacted node number below the terminal inflorescence (Fig. 1A). Five or more SD beginning when the first leaf pair expanded resulted in a similar node number below the terminal inflorescence as plants grown under constant SD. Delaying the beginning of SD exposures until plants had two or three nodes increased leaf number below the terminal inflorescence. However, flowering was still accelerated compared with plants grown under constant LD. Further delaying the beginning of SD exposure until plants had developed five nodes completely eliminated the promotive effects of SD, because plants flowered with a similar node number as plants grown under constant LD.

Timing and duration of SD exposure interacted to impact the number of inflorescences produced (Fig. 1B). For SD treatments beginning when plants had a single node, increasing the number of SD plants received from 5 to $30 \mathrm{SD}$ increased the number of inflorescences from 3.8 to 10.4 , respectively, whereas plants maintained under constant SD produced 9.2 inflorescences. Plants that remained under LD conditions until developing four or five nodes produced more inflorescences than plants grown under constant SD regardless of the number of SD received (Fig. 1B).

Expt. 2: Node number. Results from Expt. 1 suggested that celosia may become receptive to floral-inducing short days before unfolding of the first leaf pair. Therefore, a second experiment was conducted using two cultivars with photoperiod treatments beginning immediately after germination. In contrast to results for Expt. 1, the duration of SD exposure interacted with timing of SD exposure and cultivar to impact node number below the terminal inflorescence (Table 1). For example, 9 SD beginning 6 DAE reduced 'Gloria Scarlet' node number below the terminal inflorescence from 26.8 to 14.5 nodes but did not affect 'Fresh Look Red' node number. Exposure to 9 SD beginning 0 or 3 DAE did not impact node number at flowering for either cultivar.

'Gloria Scarlet' was sensitive to inductive photoperiods earlier in development than 'Fresh Look Red'. For example, 12 SD beginning 0 DAE did not impact node number below the terminal inflorescence of 'Fresh Look Red' compared with constant LD, whereas the same treatment reduced 'Gloria Scarlet Red' node number at flowering to 19.4 nodes compared with 26.8 nodes for constant LD (Table 1). However, 'Gloria Scarlet' flowering was still delayed compared with plants grown under constant SD, which formed 11.6 nodes below the terminal inflorescence.

"Saturating" SD exposures were considered to be those resulting in a statistically similar node number below the first inflorescence as the constant SD treatment. Exposing seedlings to $12 \mathrm{SD}$ beginning 3 DAE resulted in a similar node number below the first inflorescence as constant SD for 'Gloria Scarlet', whereas 'Fresh Look Red' flowering was delayed compared with constant SD (Table 1). As few as 6 SD beginning 12 DAE resulted in similar node number below the terminal inflorescence as constant SD for 'Gloria Scarlet', whereas 'Fresh Look Red' required $9 \mathrm{SD}$ or more.

Exposing 'Fresh Look Red' seedlings to 1 or $3 \mathrm{SD}$ did not reduce node number below the first flower compared with constant LD regardless of when SD exposures began. In contrast, $3 \mathrm{SD}$ beginning $12 \mathrm{DAE}$ reduced 'Gloria Scarlet' node number below the terminal inflorescence to 21.3 nodes compared with 26.8 nodes for constant LD. However, flowering was still delayed compared with constant SD.

Inflorescence number, branching, and shoot dry weight. Timing of flowering (both node number below the terminal inflorescence and days to visible inflorescence) was highly correlated positively with inflorescence number, branch number, and shoot dry weight (Table 2). That is, photoperiod treatments that resulted in earliest flowering (lower node number below the terminal inflorescence) also resulted in reductions in inflorescence number, branch number, and shoot dry weight. Additionally, inflorescence number, branch number, and shoot dry weight at flowering were all highly correlated with each other (Table 2).

Both cultivars produced more inflorescences when grown under constant LD than under constant SD conditions (Fig. 2A-B). For both 'Fresh Look Red' and 'Gloria Scarlet', increasing the number of SD from 0 to 6 beginning 12 DAE decreased the number of inflorescences from 18 and 21 , respectively, to 1 inflorescence for each cultivar (Fig. 2A-B). For both cultivars, 12 SD beginning 6,9 , or 12 DAE reduced inflorescence number compared with plants grown under constant $\mathrm{SD}$

Similar to inflorescence numbers, both cultivars produced considerably more lateral 


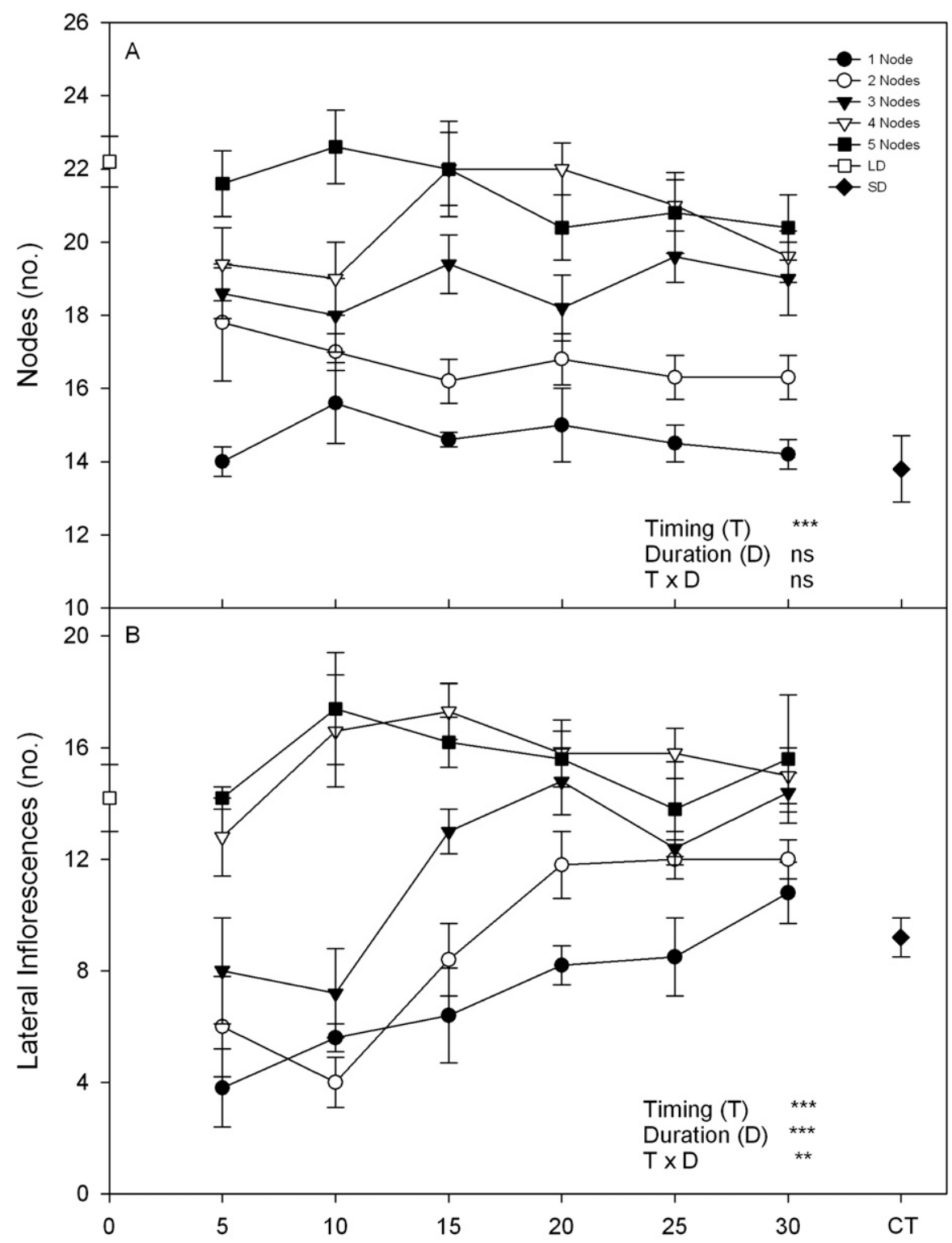

Duration of SD (d)

Fig. 1. Effect of exposing Celosia argentea var. plumosa 'Gloria Scarlet' plants to a 9-h photoperiod (SD) either continuously (CT) or for varying durations beginning after the development of varying node numbers on (A) node number below the terminal inflorescence and $(\mathbf{B})$ the number of inflorescences. Exposures began after plants had developed between one and five nodes. Continuous long-day (i.e., $0 \mathrm{~d}$ of SD; 9-h photoperiod plus night-interruption lighting; LD) and SD exposures began when plants developed one node. Before and after SD exposures, plants were grown under LD. Data points are means \pm SE $(n=10)$. Analyses of variance were conducted excluding the constant LD and SD treatments. NS, ${ }^{* *}$, and $* * *$ denote nonsignificance or significance at $P<0.01$ or $P<0.001$, respectively.

branches when grown under constant LD compared with constant SD (Fig. 2C-D). In fact, growing plants under constant SD almost completely eliminated lateral branching for both cultivars (Fig. 2C-D). Similarly, 6 or more SD beginning 12 DAE almost completely eliminated lateral branching for 'Gloria Scarlet' (Fig. 2C), whereas 'Fresh Look Red' required 9 or more SD beginning 12 DAE for a similar response (Fig. 2D).

'Gloria Scarlet' plants grown under constant SD had the lowest shoot dry weight of any of the treatments used in this experiment (Fig. 2E). 'Fresh Look Red' plants grown under constant SD also produced very low shoot dry weight with similar mass as plants exposed to 9 or more SD beginning $9 \mathrm{DAE}$ or 6 or more SD beginning 12 DAE (Fig. 2F). 'Fresh Look Red' generally produced greater shoot dry weight at first flowering than 'Gloria Scarlet' regardless of treatment (Fig. 2E-F).

\section{Discussion}

The results presented here demonstrate that celosia becomes sensitive to floralinducing SDs very early in development before complete unfolding of the first true leaves. The minimum number of SDs resulting in a similar node number below the terminal inflorescence as growing under constant SD was 5 SD for 'Gloria Scarlet' when treatments began after complete unfolding of the first leaf pair (Fig. 1A), 6 SD for 'Gloria Scarlet' (beginning 12 DAE), and 9 SD for 'Fresh Look Red' (beginning 9 DAE) when exposures began before first leaf unfolding (Table 1). For 'Gloria Scarlet' only, as few as 3 SD beginning 12 DAE accelerated flowering compared with constant LD, indicating variability in photoperiod sensitivity across cultivars. Together, these results suggest that celosia becomes sensitive to floral-inducing $\mathrm{SDs} \approx 9$ to $12 \mathrm{DAE}$, when the first true leaf pair is less than $10 \%$ of final leaf length (data not presented). Understanding when photoperiodic plants become sensitive to inductive photoperiods is critical for proper crop management, allowing growers to either promote early flowering to reduce crop production time or intentionally delay flowering. For example, after pinching, LDs are often provided to the SD plant poinsettia (Euphorbia pulcherrima Willd. ex Klotzsch.) to delay flower initiation (Snipen et al., 1999) and allow lateral branch development.

The length of the photoperiod-insensitive juvenile phase has been determined for only a few bedding plant species. Petunia 'Express Blush Pink' grown at $19.2{ }^{\circ} \mathrm{C}$ had a juvenile period length of $16.3 \mathrm{~d}$ (Adams et al., 1999). Adams et al. (2003) determined that the length of the juvenile phase for seven cultivars of the LD plant Antirrhinum majus L. (snapdragon) varied between $25.6 \mathrm{~d}$ for 'Bells Red' to $40.1 \mathrm{~d}$ for 'Pirouette Purple/ White', corresponding to development of 9.9 and 28.5 leaves, respectively. Although there was variation in the length of the photoperiod-insensitive juvenile phase between the two celosia cultivars examined here, the variation was minimal, and both cultivars were receptive to inductive photoperiods shortly after the first true leaves were visible.

Results presented here suggest that celosia becomes photoperiod-sensitive for flower induction $\approx 9$ to $12 \mathrm{DAE}$ at $20{ }^{\circ} \mathrm{C}$; however, temperature can influence the duration of the juvenile phase (Adams et al., 1999; Ellis et al., 1997). For example, the length of the juvenile phase of petunia 'Express Blush Pink' decreased from 21.0 to $12.5 \mathrm{~d}$ as temperature increased from 13.7 to $22.3{ }^{\circ} \mathrm{C}$ and then increased to 15.2 or $17.6 \mathrm{~d}$ as temperature increased further to 25 or 28.7 ${ }^{\circ} \mathrm{C}$, respectively (Adams et al., 1999). Although the length of the juvenile phase may vary with temperature, it is clear that to control flowering time in celosia, the photoperiod environment must be managed soon after seed germination. Failure to do so may result in premature flowering and an associated decrease in crop quality.

The two cultivars examined here also exhibited variation in the minimum number of SDs required to minimize node number below the terminal inflorescence. For 'Gloria Scarlet', plants exposed to $6 \mathrm{SD}$ beginning 12 
Table 1. Effect of the duration and timing of short-day (SD) exposures, or continuous exposure to either SD or long days (LD), on average node number below the terminal inflorescence of two Celosia argentea var. plumosa cultivars. ${ }^{z}$

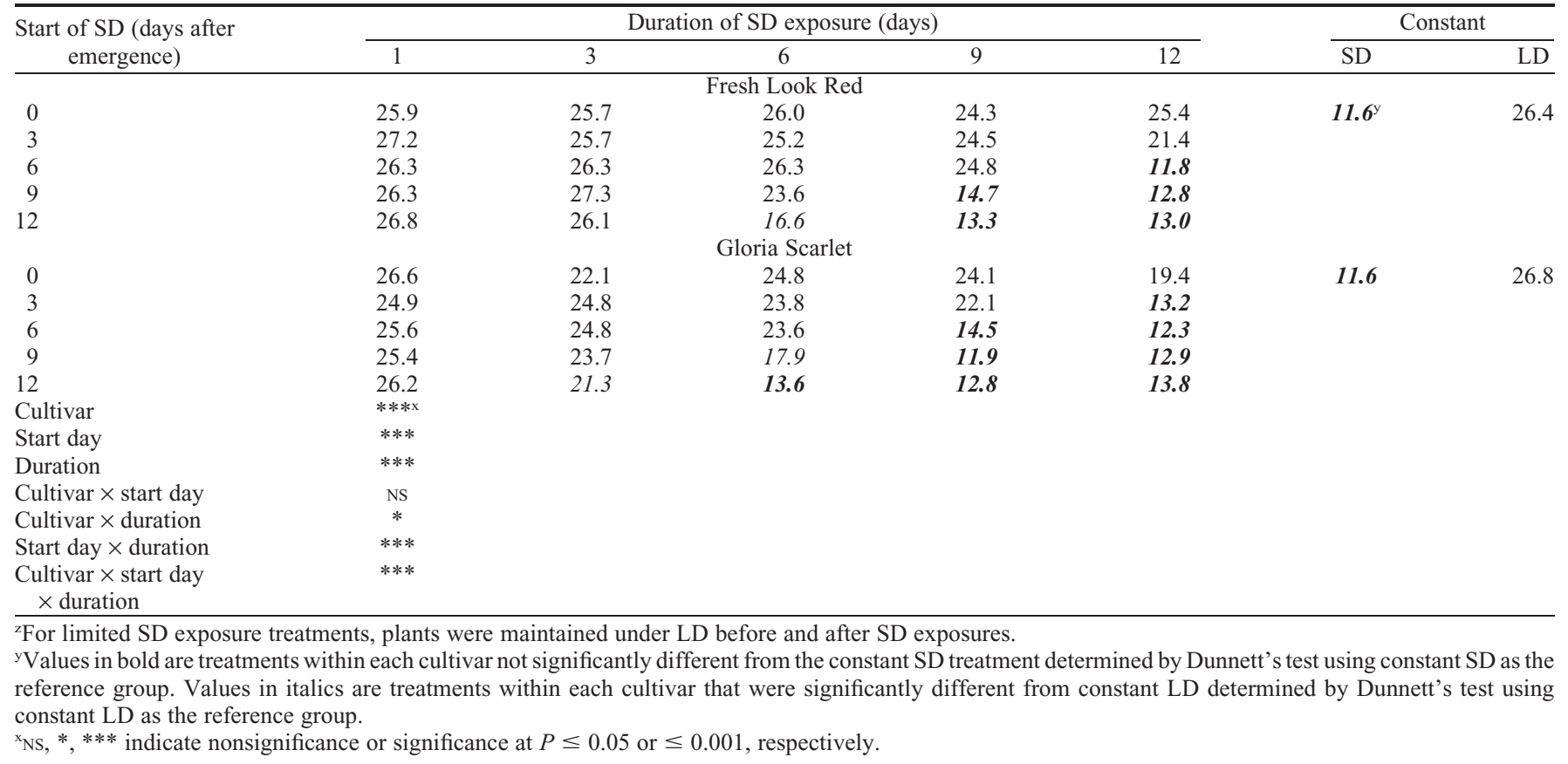

Table 2. Pearson correlation coefficients matrix for variables node number below the terminal inflorescence (Node no.), number of lateral inflorescences (Inflor. no.), number of lateral branches (Branch no.), shoot dry weight (Dry weight), and days to visible inflorescence (Days). ${ }^{z}$

\begin{tabular}{|c|c|c|c|c|c|}
\hline Variable & Node no. & Inflor. no. & Branch no. & Dry wt & Days \\
\hline Node no. & & 0.734 & 0.923 & 0.908 & 0.934 \\
\hline Branch no. & 0.923 & 0.840 & & 0.941 & 0.933 \\
\hline Dry weight & 0.889 & 0.868 & 0.929 & & 0.938 \\
\hline
\end{tabular}

${ }^{z}$ The upper right half of the matrix represents correlation coefficients for celosia 'Fresh Look Red' and the lower left half for 'Gloria Scarlet'. Values in bold represent correlations significant at $P \leq 0.001$.

DAE or later flowered with a similar node number as plants grown under constant SD (Table 1), whereas 'Fresh Look Red' required 9 SD beginning 9 DAE or later for a similar response. Similar variation has been identified across varieties of the SD plants Pharbitis nil and chrysanthemum (Adams et al., 1998; Imamura et al., 1966; Kofranek and Halevy, 1974). For example, a single 8-h photoperiod was sufficient to induce flowering of $P$. nil 'Kidachi', 'Shifukurin', 'Tendan' and 'Violet', whereas 2 and 10 SD cycles were required for 'Nepal' and 'Africa', respectively.

Celosia is a facultative SD plant, meaning it will flower under any photoperiod, but will flower earlier in development if grown under SDs. In addition to exhibiting a photoperiodinsensitive juvenile phase, facultative (or quantitative) photoperiodic plants species experience a second phase of photoperiod insensitivity with flowering occurring under previously prohibitive photoperiods. For example, the facultative LD plant petunia 'Express Blush Pink', which became photoperiod-sensitive 16.3 DAE at $19.2{ }^{\circ} \mathrm{C}$, subsequently became insensitive to photoperiod 56 DAE (Adams et al., 1999). Results presented here demonstrate that by the time
'Gloria Scarlet' plants had developed five nodes $(\approx 45 \mathrm{DAE})$, transferring plants from LD to SD did not alter timing of flowering (Fig. 1A), indicating that plants were no longer sensitive to photoperiod for flowering. The combined results of experiments presented here indicate that celosia has a relatively narrow window of photoperiod sensitivity for floral induction, occurring between $\approx 9$ and $45 \mathrm{DAE}$ at $20{ }^{\circ} \mathrm{C}$, approximately from the time of emergence of the first leaf pair to full expansion of leaves at the fifth node. At $20^{\circ} \mathrm{C}$, a new node appeared approximately every 5 to $6 \mathrm{~d}$.

The number of inflorescences produced was a function of how many nodes plants developed before SD exposure and the duration of SD exposure. Exposing plants to $5 \mathrm{SD}$ when plants had developed only one true node resulted in a similar node number below the terminal inflorescence as plants continuously grown under SD. However, the number of inflorescences produced was drastically reduced to 3.8 inflorescences per plant compared with 9.2 inflorescences for plants grown under constant SD (Fig. 1B). Increasing the duration of SD exposure increased inflorescence number, with 20 or more SD required for inflorescence number to equal that of plants grown under constant SD. Similar increases in inflorescence number with increasing SD duration occurred if exposures began when plants had developed two or three true nodes. Similarly, for the LD plant Coreopsis lanceolata L. 'Early Sunrise', as the number of LDs received increased from 6 to $18 \mathrm{~d}$, flower bud number increased from 2.5 to 5.9 buds per plant (Damann and Lyons, 1993). Inflorescence number was unaffected by duration of SD exposure if the exposures began when plants had developed four or five nodes. For the plants receiving SD exposure before expansion of the first leaf pair, inflorescence number decreased as SD duration increased from 1 to $12 \mathrm{SD}$ regardless of when SD exposure began (Fig. 2A-B).

As celosia develops a terminal inflorescence, the number of inflorescences produced is dependent on the number of lateral buds released from dormancy. The number of branches produced was highly positively correlated with timing of flowering, both days to flower and node number below the terminal inflorescence (Table 2). Treatments that promoted early flowering also reduced branch number. When 'Gloria Scarlet' plants were exposed to 6 or more SD beginning 12 


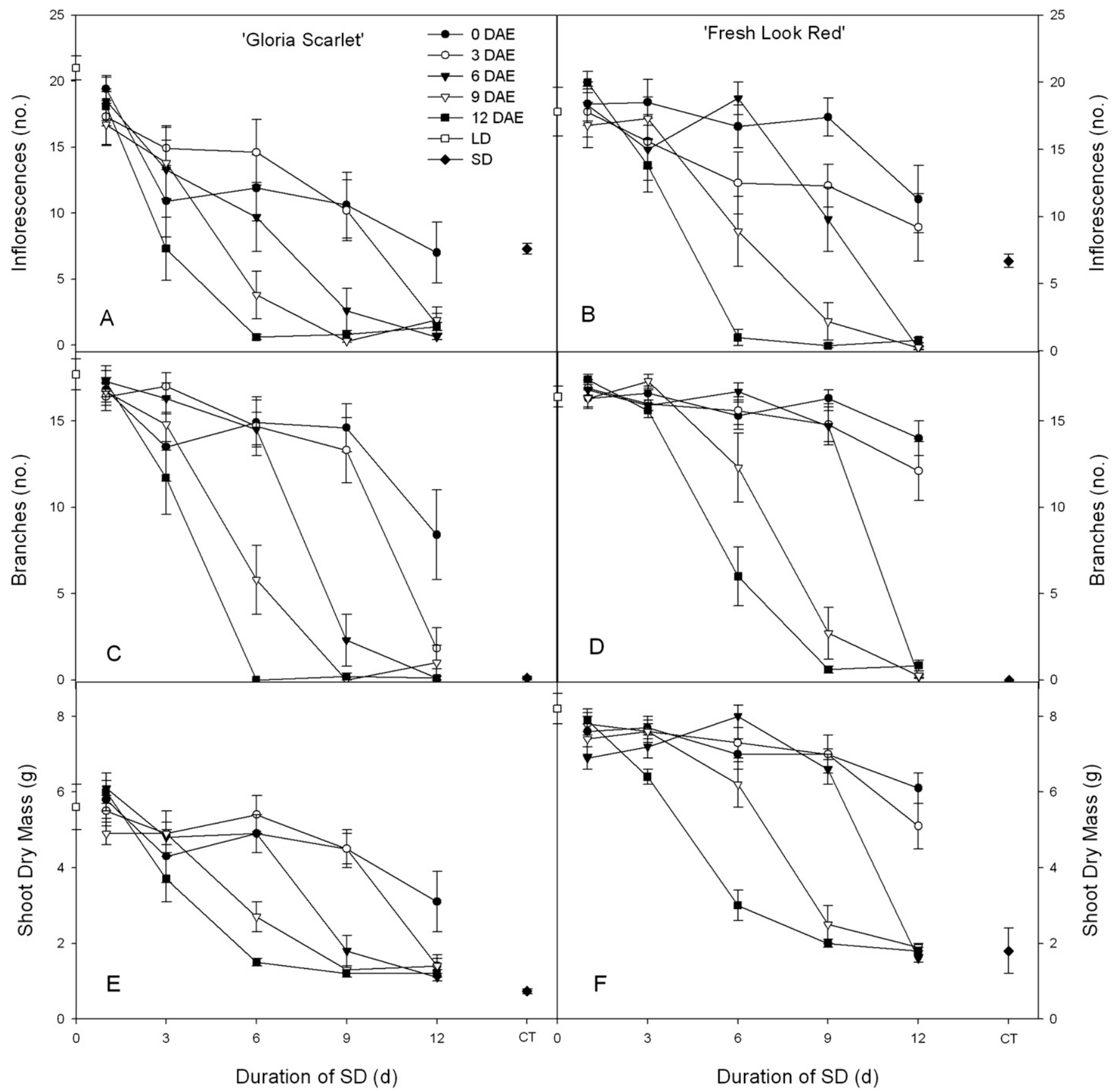

Fig. 2. Effect of exposing Celosia argentea var. plumosa 'Gloria Scarlet' (A, C, E) and 'Fresh Look Red' (B, D, F) plants to a 9-h photoperiod (SD) either continuously (CT) or for varying durations beginning after the development of varying node numbers on the number of inflorescences (A-B), number of branches $(\mathbf{C}-\mathbf{D})$, and shoot dry weight $(\mathbf{E}-\mathbf{F})$. Short-day exposures began after varying numbers of days after emergence (DAE) of seedlings. Continuous longday (i.e., $0 \mathrm{~d}$ of SD; 9-h photoperiod plus night-interruption lighting; LD) and SD exposures began 0 DAE. Before and after SD exposures, plants were grown under LD. Data points are means \pm SE $(n=12)$.

DAE, the treatment resulting in earliest flowering, lateral branching was completely inhibited (Fig. 2C). Although branch number and inflorescence number were also highly correlated (Table 2), not all branches developed an inflorescence. 'Fresh Look Red' plants exposed to $6 \mathrm{SD}$ beginning $12 \mathrm{DAE}$ produced six branches, but only a single inflorescence (Figs. 2B and D). Delaying flower initiation of 'Gloria Scarlet' by maintaining plants under LD conditions until one or more true nodes had developed increased inflorescence number (Fig. 1B) and branch number (data not shown). In some SD species such as chrysanthemum (Schwabe, 1951), transferring plants to LDs after floral induction and initiation under SDs can inhibit floral development, particularly if the transfer occurs early in floral development. In the current studies, it is not known whether the low inflorescence numbers observed in some treatments were the result of a lack of floral initiation in lateral buds or failed development of initiated floral buds, because microscopic evaluation of the lateral buds was not performed.

The results demonstrate that celosia becomes receptive to inductive photoperiods early in development. Therefore, to prevent premature flowering and the associated reduction in crop quality, plants must be grown under LD conditions starting before plants become receptive to photoinductive SDs $(\approx 9 \mathrm{DAE})$ if the ambient photoperiod is short. Maintaining plants under constant LD conditions resulted in the highest crop quality as evidenced by increased inflorescence number, branching, and shoot dry weight at flowering. However, crop production time was also greatest in this treatment.

Knowing when plants become receptive to inductive photoperiods and the effects of 
photoperiod regimes on crop quality characteristics will allow commercial growers to develop production schedules that balance the desire to reduce crop production time with the necessity to maintain acceptable crop quality.

\section{Literature Cited}

Adams, S., S. Pearson, and P. Hadley. 1998. An appraisal of the use of reciprocal transfer experiments: Assessing the stages of photoperiod sensitivity in chrysanthemum cv. Snowdon (Chrysanthemum morifolium Ramat.). J. Expt. Bot. 49:1405-1411.

Adams, S.R., M. Munir, V.M. Valdes, F.A. Langton, and S.D. Jackson. 2003. Using flowering times and leaf numbers to model the phases of photoperiod sensitivity in Antirrhinum majus L. Ann. Bot. (Lond.) 92:689-696.

Adams, S.R., S. Pearson, P. Hadley, and W.M. Patefield. 1999. The effects of temperature and light integral on the phases of photoperiod sensitivity in Petunia $\times$ hybrida. Ann. Bot. (Lond.) 83:263-269.

Anderson, N.O. (ed.). 2006. Flower breeding and genetics: Issues, challenges and opportunities for the 21 st century. Springer, Dordrecht, The Netherlands.

Clark, J.R. 1983. Age-related changes in trees. J. Arboriculture 9:201-205.

Cumming, B.G. 1959. Extreme sensitivity of germination and photoperiodic reaction in the genus Chenopodium (Tourn.). Nature 185: 1044-1045.

Damann, M.P. and R.E. Lyons. 1993. Juvenility, flowering, and the effects of a limited inductive photoperiod in Coreopsis grandiflora and $C$. lanceolata. J. Amer. Soc. Hort. Sci. 118:513518.

Ellis, R.H., A. Qi, P.Q. Craufurd, R.J. Summerfield, and E.H. Roberts. 1997. Effects of photoperiod, temperature and asynchrony between thermoperiod and photoperiod on development to panicle initiation in sorghum. Ann. Bot. (Lond.) 79:169-178.

Erwin, J.E. and R.M. Warner. 2002. Determination of photoperiodic response group and effect of supplemental irradiance on flowering of several annual bedding plant species. Acta Hort. 580:95-99.

Friend, D.J.C. 1968. Photoperiodic responses of Brassica campestris cv. Ceres. Physiol. Plant. 21:990-1002.

Garner, W.W. and H.A. Allard. 1920. Effect of the relative length of day and night and other factors of the environment on growth and reproduction in plants. J. Agr. Res. 18:553606.

Hartmann, H.T. 1947. Some effects of temperature and photoperiod on flower formation and runner production in the strawberry. Plant Physiol. 22:407-420

Imamura, S., M. Muramatsu, S. Kitajo, and A. Takimoto. 1966. Varietal difference in photoperiodic behavior of Pharbitis nil. Bot. Mag. Tokyo 79:714-721.

Ito, H. and T. Saito. 1962. Studies on the flower formation in the strawberry plant. I. Effects of temperature and photoperiod on the flower formation. Tohoku J. Agr. Res. 13:191-203.

Kobayashi, Y. and D. Weigel. 2007. Move on up, it's time for change mobile signals controlling photoperiod-dependent flowering. Genes Dev. 21:2371-2384.
Kofranek, A.M. and A.H. Halevy. 1974. Minimum number of short days for production of high quality standard chrysanthemums. HortScience 9:543-544.

Mattson, N.S. and J.E. Erwin. 2005. The impact of photoperiod and irradiance on flowering of several herbaceous ornamentals. Scientia Hort. 104:275-292.

Piringer, A.A. and H.A. Borthwick. 1961. Effects of photoperiod and kind of supplement light on growth, flowering, and stem fasciation of celosia. Amer. J. Bot. 48:588-592.

Schwabe, W.W. 1951. Factors controlling flowering in the chrysanthemum: II. Day-length effects on the further development of inflorescence buds and their experimental reversal and modification. J. Expt. Bot. 2:223-237.

Snipen, L.G., R. Moe, and J. Søreng. 1999. Influence of potential growth factors in predicting time to flowering in poinsettia (Euphorbia pulcherrima). Scientia Hort. 81:345-359.

Thomas, B. and D. Vince-Prue. 1997. Photoperiodism in plants. Academic Press, Inc., San Diego, CA.

Thompson, D.J. and D.G. Stout. 1991. Duration of the juvenile period in diffuse knapweed ( $\mathrm{Cen}$ taurea diffusa). Can. J. Bot. 69:368-371.

Verheul, M.J., A. Sønsteby, and S.O. Grimstad. 2006. Interactions of photoperiod, temperature, duration of short-day treatment and plant age on flowering of Fragaria $\times$ ananassa Duch. cv. Korona. Scientia Hort. 107:164-170.

Wang, Z., M.C. Acock, and B. Acock. 1997. Photoperiod sensitivity during flower development of opium poppy (Papaver somniferum L.). Ann. Bot. (Lond.) 79:129-132. 